\title{
Glutamatergic Neuronal Differentiation of Mouse Embryonic Stem Cells after Transient Expression of Neurogenin 1 and Treatment with BDNF and GDNF: In Vitro and In Vivo Studies
}

\author{
Jeannie H. Reyes, ${ }^{1,2}$ K. Sue 0'Shea, ${ }^{2}$ Noel L. Wys, ${ }^{1}$ J. Matthew Velkey, ${ }^{2}$ Diane M. Prieskorn, ${ }^{1}$ Karolina Wesolowski, ${ }^{1}$ \\ Josef M. Miller, ${ }^{1}$ and Richard A. Altschuler ${ }^{1,2}$ \\ ${ }^{1}$ Kresge Hearing Research Institute, Department of Otolaryngology, and ${ }^{2}$ Department of Cell and Developmental Biology, University of Michigan, Ann \\ Arbor, Michigan 48109-0506
}

\begin{abstract}
Differentiation of the pluripotent neuroepithelium into neurons and glia is accomplished by the interaction of growth factors and cell-type restricted transcription factors. One approach to obtaining a particular neuronal phenotype is by recapitulating the expression of these factors in embryonic stem (ES) cells. Toward the eventual goal of auditory nerve replacement, the aim of the current investigation was to generate auditory nerve-like glutamatergic neurons from ES cells. Transient expression of Neurogl promoted widespread neuronal differentiation in vitro; when supplemented with brain-derived neurotrophic factor (BDNF) and glial cell line-derived neurotrophic factor (GDNF), 75\% of ES cell-derived neurons attained a glutamatergic phenotype after $5 \mathrm{~d}$ in vitro. Mouse ES cells were also placed into deafened guinea pig cochleae and Neurog1 expression was induced for $48 \mathrm{~h}$ followed by $26 \mathrm{~d}$ of BDNF/GDNF infusion. In vivo differentiation resulted in $50-75 \%$ of ES cells bearing markers of early neurons, and a majority of these cells had a glutamatergic phenotype. This is the first study to report a high percentage of ES cell differentiation into a glutamatergic phenotype and sets the stage for cell replacement of auditory nerve.
\end{abstract}

Key words: stem cells; development; glutamate; auditory; cochlea; cell fate; neurogenesis; neuron

\section{Introduction}

Embryonic stem (ES) cells have the potential to replace tissues lost by injury, disease, or normal aging if lineage differentiation can be controlled. Replicating the intrinsic and extrinsic factors influencing fate choice provides one possible method toward obtaining the specific phenotype of interest for stem cell therapies. Delivery of such cues to ES cells in vivo can be particularly challenging, and transplantation studies face the additional obstacle of immune rejection, which may be circumvented by implantation of undifferentiated ES cells (Drukker et al., 2006; Robertson et al., 2007), followed by differentiation in vivo.

Glutamatergic spiral ganglion neurons (SGN) that make up the auditory nerve convey sensory information from inner hair cells (IHCs) to the CNS, and are particularly susceptible to death secondary to IHC loss. Regeneration of SGN does not occur endogenously. The advent of new technologies such as cochlear implants has accelerated the need to replace SGN to improve efficacy of these devices, which rely on surviving neurons to re-

\section{Received Sept. 30, 2008; accepted 0ct. 8, 2008.}

This work was supported by National Institutes of Health Grants DC03820 (R.A.A., J.M.M.), GM069985 (K.S.O.), NS04187 (K.S.0.), P30 DC05188, and by General Motors/United Auto Workers funds. We thank Dr. Maria Morrell for discussion of optimal cell culture techniques and for sharing the GFAP antibody. We also thank Prof. Kate Barald for discussions regarding embryonic stem cell differentiation.

Correspondence should be addressed to Richard A. Altschuler, Kresge Hearing Research Institute, University of Michigan, 1150 West Medical Center Drive, Ann Arbor, MI 48109-5616. E-mail: shuler@umich.edu.

DOI:10.1523/JNEUROSCI.0563-08.2008

Copyright $\odot 2008$ Society for Neuroscience $\quad 0270-6474 / 08 / 2812622-10 \$ 15.00 / 0$ store hearing. Previous reports have found that placement of ES cells or tissue-derived stem cells into the relatively immunoprivileged cochlea eventually yielded a small percentage of neurons, whereas a majority of implanted cells differentiated into glia $(\mathrm{Hu}$ et al., 2004, 2005a,b; Tamura et al., 2004; Nicholl et al., 2005; Coleman et al., 2006, 2007; Corrales et al., 2006; Parker et al., 2007; Ulfendahl et al., 2007). Chronic intrascalar application of neurotrophic factors (NTFs) increased the number of stem cells that displayed a neuronal phenotype, but the percentage was still $<25 \%$ (Altschuler et al., 2008).

Neurogenin 1 (Neurog1) is a proneural basic helix loop helix (bHLH) transcription factor that activates a downstream cascade of NeuroD1, Brn3a, GATA3, and NTF receptors necessary for normal SGN differentiation, migration, and survival (Huang et al., 2001; Karis et al., 2001; Fritzsch, 2003). Mice deficient in Neurog1, NeuroD1, or Brn3a display varying degrees of SGN disruption, with SGNs completely absent in Neurog1 null mice (Ma et al., 2000; Huang et al., 2001; Kim et al., 2001). Overexpression of Neurog1 in neural progenitors promotes neuronal differentiation while inhibiting gliogenesis, even in the presence of glial-inducing factors (Sun et al., 2001).

In the present study, we develop a more efficient approach that allows us to guide ES cell differentiation in vivo. We hypothesized that ES cells could be differentiated toward a glutamatergic neuronal phenotype by inducing neural gene expression with Neurog1, followed by providing endogenous cues to further hone the target phenotype and/or promote survival of the desired phe- 


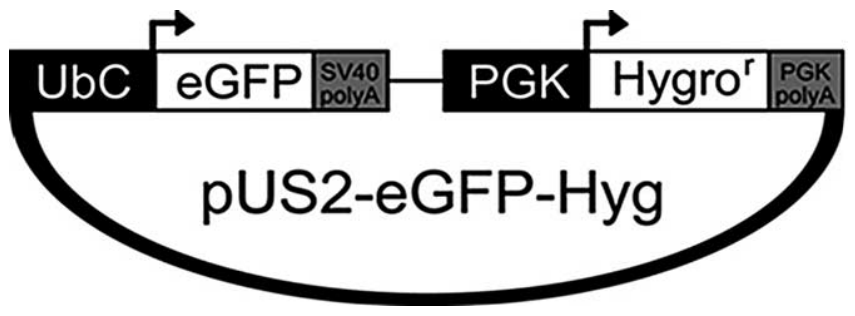

Figure 1. The N7-Neurog1 parent line was transfected with an eGFP expression cassette driven by the human ubiquitin ligase $\mathrm{C}(\mathrm{UbC})$ promoter.

notype. Neurog 1 is expressed for $48 \mathrm{~h}$ in the developing embryonic otocyst (McCormick et al., 1996; Fritzsch, 2003). We tested whether $48 \mathrm{~h}$ transient Neurog1 expression in pluripotent mouse ES cells, combined with brain-derived neurotrophic factor (BDNF) and glial cell line-derived neurotrophic factor (GDNF) treatment could promote ES cell differentiation toward a SGNlike phenotype for auditory nerve replacement.

\section{Materials and Methods}

Inducible Neurog1 embryonic stem cell line. ES cells were derived from a parent mouse ES cell line (N7) (Velkey, 2005) containing a tet-inducible Neurog1. The N7 cell line contains a reverse tet transactivator upstream of the constitutively active ROSA26 locus that is puromycin selectable (Kyba et al., 2002). To derive the N7 line, a plasmid containing the Neurog 1 cDNA and an ATG start codon was integrated into the ES cell genome upstream of a tet operon. Downstream of the integration site, a truncated neomycin resistance cassette was placed into the line (Velkey, 2005), making it G418 selectable.

Cell culture and transfection. To track implanted cells, the N7 cell line was transfected with a plasmid containing enhanced green fluorescent protein (eGFP) driven by the human ubiquitin ligase $\mathrm{C}$ (UbC) promoter (Wulff et al., 1990; Schorpp et al., 1996) (Fig. 1). The cell line had been previously modified with eGFP driven by the CMV promoter, but we found this construct to be susceptible to methylation on differentiation. N7-Neurog1 $\left(2.75 \times 10^{6}\right)$ cells were plated in a $6 \mathrm{~cm}$ dish and allowed to grow to $60-70 \%$ confluency. The cells were transfected with $2 \mu \mathrm{g}$ of the UbC-eGFP-Hyg ${ }^{\mathrm{R}}$ DNA using lipofectamine and PLUS reagent (Invitrogen). Selection with hygromycin for cells that integrated the new UbC construct was followed by identification of individual colonies with well defined edges uniformly expressing eGFP. Colonies were transferred to a 96-well plate and dissociated with trypsin and EDTA. Colonies that survived additional selection in puromycin $(2 \mu \mathrm{g} / \mathrm{ml})$ and hygromycin (300 $\mu \mathrm{g} / \mathrm{ml}$ ) were expanded to $75 \mathrm{~cm}^{2}$ flasks in ES cell maintenance medium consisting of sterile-filtered DMEM (Invitrogen) with 10\% ES cell-tested fetal bovine serum (Atlanta Biologicals), $5 \%$ embryonic stem cell supplement (DMEM with $24 \mathrm{mg} / \mathrm{ml}$ HEPES buffer, $4 \mathrm{mg} / \mathrm{ml} \mathrm{L}$-glutamine, and $70 \mathrm{ng} / \mathrm{ml} \beta$-mercaptoethanol) and $0.5 \mu \mathrm{g} / \mathrm{ml}$ leukemia inhibitory factor (LIF) (Millipore). One subclone, K9, was chosen based on continuous, homogenous bright eGFP expression 24-48 h after Doxycyclineinduced (Dox) differentiation of cells in vitro.

Differentiation in vitro. K9 ES cells were expanded in $75 \mathrm{~cm}^{2}$ flasks to $\sim 80 \%$ confluency and then plated for differentiation. Cells were washed with $1 \times$ HBSS (Invitrogen) to remove growth medium and cellular debris, and then dissociated using $0.25 \%$ trypsin and $1 \mathrm{~mm}$ EDTA in $1 \times$ HBSS for 2 min at $37^{\circ} \mathrm{C}$. Dissociation was blocked using complete medium without LIF and cell clumps were triturated to a single-cell suspension. Cells were resuspended in serum-free differentiation medium $[80 \%$ F12/DMEM; (Invitrogen), 20\% Neurobasal medium (Invitrogen), with $\mathrm{B} 27$ and $\mathrm{N} 2$ supplements, and $10 \mathrm{~mm}$ sodium pyruvate (Invitrogen); 80:20 media]. Cells $\left(5 \times 10^{5}\right)$ per well were plated in 6-well plates. Four sterile, $13 \mathrm{~mm}$ diameter Thermanox cell culture coverslips were placed at the bottom of each well and coated with $0.1 \%$ gelatin (Sigma).

Expression of the Neurog1 transgene was induced by exposure to 1 $\mu \mathrm{g} / \mathrm{ml}$ Dox (Sigma) for $48 \mathrm{~h}$, with and without BDNF (20 $\mathrm{ng} / \mathrm{ml}$; QED Bioscience) and GDNF (100 ng/ml; Amgen). After $3 \mathrm{~d}$ in culture with half-medium changes every $24 \mathrm{~h}$, the serum-free medium was replaced with DMEM containing 5\% knock-out serum replacement (Invitrogen) and 5\% ES cell supplement without Dox to promote long-term survival.

In vitro assessment: immunostaining. Cells were fixed in $4 \%$ paraformaldehyde for $15 \mathrm{~min}$ at $24 \mathrm{~h}, 72 \mathrm{~h}$, and $5 \mathrm{~d}$. Coverslips from three replicate cultures were washed in phosphate buffered saline (Dulbecco's PBS; Invitrogen) and incubated overnight at $4^{\circ} \mathrm{C}$ with the antibodies to Neurog1 (1:100; Millipore), the neuronal marker TUJ1 (class III $\beta$-tubulin, 1:300; Covance), VGLUT1 and VGLUT2 (both 1:500; Synaptic Systems), and glial fibrillary acidic protein (GFAP, 1:1500; Advance Immunochemical) diluted in $0.1 \%$ Triton-X in PBS. The coverslips were washed with D-PBS and TUJ1 binding was visualized using an Alexa 633 secondary (1:500; Invitrogen). VGLUT1 and VGLUT2 were visualized using Alexa $594 \mathrm{~nm}$ (1:500; Invitrogen). GFAP was visualized with Alexa 568 (1:300; Invitrogen).

In each treatment group, the cell number from three coverslips from each of the three replicate cultures was quantified ( $n=9$ coverslips/ group). Nine images were taken from each coverslip using an Olympus FluoView 500 Confocal microscope ( $n=81$ images/treatment group). The total number of neurons present was estimated as the number of cells positive for TUJ1 only, TUJ1 and eGFP, and TUJ1 and VGLUT1/2. The number of cells colabeled for TUJ1 and VGLUT1/2 was taken to be the total number of neuronal, glutamatergic cells. The total number of cells was estimated as the total number of neuronal cells plus the number of cells positive for eGFP only, VGLUT1/2 only, GFAP and TUJ1, and GFAP only. Hoechst 33258 stain revealed normal nuclei as well as sparse, tiny puncta of nuclei in dead cells that did not coexpress any of these markers.

In vitro assessment: quantitative real-time PCR. ES cells from three treatment groups (uninduced control at $0 \mathrm{~h}, 72 \mathrm{~h}$ Dox with NTFs, and $5 \mathrm{~d}$ Dox with NTFs) were examined using quantitative real-time PCR (qRTPCR) for the expression of NTF receptors Ntrk1, Ntrk2, Ntrk3 and the $\alpha$ subunit of the GDNF receptor. Additionally, qRT-PCR was performed for Neurog 1 and three of its downstream targets upregulated during SGN differentiation: Brn3a, GATA3 and NeuroD1. All TaqMan Gene Expression Assays were purchased from Applied Biosystems.

Cells $\left(5 \times 10^{5}\right)$ were plated on $0.1 \%$ gel-coated 6-well dishes in 80:20 differentiation medium containing Dox and NTFs. Three experimental replicates were performed. At $0 \mathrm{~h}, 72 \mathrm{~h}$ and $5 \mathrm{~d}$, cells were washed with $1 \times$ HBSS to remove medium and RNA was extracted using the RNeasy Mini Kit (Qiagen) according to the manufacturer's protocol. RNA integrity and concentrations were obtained using the Agilent Bioanalyzer 2100 . Only RNA with an integrity number $>9.0$ was used. $1 \mu \mathrm{g}$ of RNA from each treatment group was converted to cDNA using the High Capacity cDNA Reverse Transcription Kit (Applied Biosystems). Each experimental replicate was assessed in triplicate using the ABI PRISM 7900HT Sequence Detection System analyzer for Real Time PCR, which gives a threshold cycle $\left(\mathrm{C}_{\mathrm{T}}\right)$ number. $\mathrm{C}_{\mathrm{T}}$ was normalized to the GAPDH housekeeper (Murphy and Polak, 2002), and then used to calculate fold changes in gene expression using the $2^{-\Delta \Delta C}$ method (Livak and Schmittgen, 2001). Fold changes for the $72 \mathrm{~h}$ and $5 \mathrm{~d}$ treatment groups were taken as any increase in gene expression compared with uninduced controls at $0 \mathrm{~h}$ and were plotted on a log scale.

Preparation of mouse ES cells for in vivo placement. The K9 cell line was grown to $80 \%$ confluency in ES cell maintenance medium as described above, and dissociated using Hanks-based enzyme-free cell dissociation buffer (Invitrogen) with $1 \mathrm{~mm}$ EDTA into a single-cell suspension immediately before implantation. Cells were resuspended in serum-free differentiation medium without Dox and diluted to a concentration of $5 \times 10^{4}$ cells per microliter immediately before implantation. Cell viability was assessed by staining a small sample $(<5 \mu \mathrm{l})$ with trypan blue before and after the surgeries were completed.

Guinea pig deafening. National Institutes of Health strain guinea pigs (Elm Hill Breeding Lab), weighing 275-315 g, were systemically deafened. Subcutaneous administration of $450 \mathrm{mg} / \mathrm{kg}$ kanamycin was followed by anesthesia with ketamine/xylazine then $60 \mathrm{mg} / \mathrm{kg}$ ethacrynic acid was administered intravenously (jugular vein) $2 \mathrm{~h}$ later. This results in nearly complete loss of inner and outer hair cells and subsequent loss of SGN. Auditory brainstem responses were taken to confirm deafening. 
In vivo placement of mouse ES cells and neurotrophic factor infusion. ES cells were slowly aspirated into a $30 \mathrm{~g}$ needle and $1 \mathrm{ml}$ syringe. The needle was introduced into the lumen of a PE10 cannula, the cannula filled and the needle removed. A glass microliter syringe and $30 \mathrm{~g}$ needle filled with saline was then introduced into the PE cannula. The opposite end of the cannula (a modified 33 g needle) was inserted into scala tympani (ST) through a cochleostomy in the base of the cochlea and into the osseous spiral lamina at a ventral angle with a small puncture of the modiolar wall. After a slow bolus injection of 250,000 cells in $5 \mu$ l, the cannula was left in place for $10 \mathrm{~min}$. It was then replaced by a cannula into ST filled with $25 \mu \mathrm{l}$ of Doxycycline (Bedford Laboratories) at a concentration of $10 \mu \mathrm{g} / \mathrm{ml}$, sufficient for $2 \mathrm{~d}$ of Dox infusion. The cannula was attached to an osmotic pump (Alzet; model 2002, $14 \mathrm{~d}$ reservoir, flow rate $0.5 \mu \mathrm{l} / \mathrm{hr}$ ) containing BDNF $100 \mu \mathrm{g} / \mathrm{ml}$ and GDNF $10 \mu \mathrm{g} / \mathrm{ml}$ for $14 \mathrm{~d}$ of delivery and the pump was then implanted subcutaneously on the back (Prieskorn and Miller, 2000). The pump was changed at $3 \mathrm{~d}$, to allow a total of $27 \mathrm{~d}$ of NTF infusion (2 d Dox, $25 \mathrm{~d}$ BDNF/GDNF) into the ST. As controls, three animals (GP 6, 7 and 8 ) received stem cells, but were only infused with BDNF/GDNF without the $2 \mathrm{~d}$ of Dox to induce Neurog1.

Fixation and sectioning. Four weeks after intrascalar placement of ES cells (8-9 weeks after deafening), animals were heavily anesthetized with $0.5 \mathrm{ml}$ of sodium pentobarbital intraperitoneally (FatalPlus; Vortech) followed by transcardiac perfusion with phosphate buffered saline, then $4 \%$ paraformaldehyde in phosphate buffer. The cochleae were then carefully removed, membranes of the round and oval windows were opened with a fine tipped forceps, an opening made in the otic capsule at the apex and the cochlea placed into the same fixative for $4 \mathrm{~h}$. Cochleae were then decalcified in 5\% EDTA for $5-10 \mathrm{~d}$ at $4^{\circ} \mathrm{C}$. Cochleae were cryoprotected in increasing concentrations of sucrose in PBS (5-20\%) over $2 \mathrm{~d}$ followed by PBS/20\% sucrose/OCT mixture for 15 min under vacuum pressure. Finally, the cochleae were flash frozen in $20 \%$ sucrose/OCT in isopentane cooled in liquid nitrogen. Six micrometer cryostat sections were cut in a paramodiolar plane.

Immunocytochemistry and in situ hybridization. Mid-modiolar sections were identified based on gross visual assessment, generally 25-30 such sections were obtained from each cochlea. Three sections were assessed for eGFP staining only. Three sections (sections 11, 16 and 21) were used for coimmunolabeling with mouse monoclonal antibody to TUJ1 and polyclonal antibodies to vesicular glutamate transporter 1 and vesicular glutamate transporter 2 (both at 1:500). The three adjacent sections were immunostained with polyclonal rabbit antibody to GFAP. Fluorescent in situ hybridization (FISH) localization of mouse genomic DNA and immunostaining for TUJ1 was performed on sequential sections. Semiadjacent sections were also immunostained with polycolonal rabbit antibody to GATA3 or to NeuroD1.

For immunohistochemistry, sections were pretreated with Universal Blocking Reagent (BioGenex) for $10 \mathrm{~min}$ at room temperature and then processed for immunocytochemistry as described above. Sections were coverslipped using FluoroMount G (SouthernBiotech) mounting medium. FISH was performed using mouse COT-1 DNA (Invitrogen) to identify mouse genomic DNA. The probe was labeled using digoxigenin16-dUTP and a nick translation kit (both from Roche Applied Science) following the manufacturer's instructions. To visualize the hybridization signal, slides were incubated with rhodamine labeled anti-digoxigenin
$24 \mathrm{~h}$

年
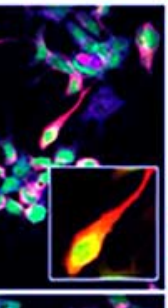

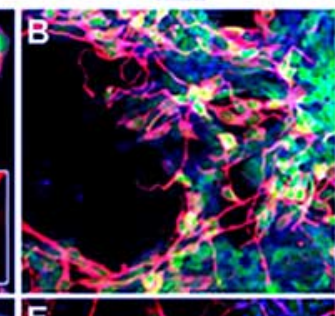

$\underline{72 h}$
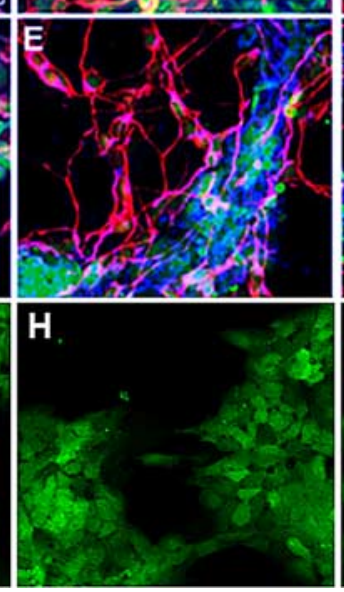
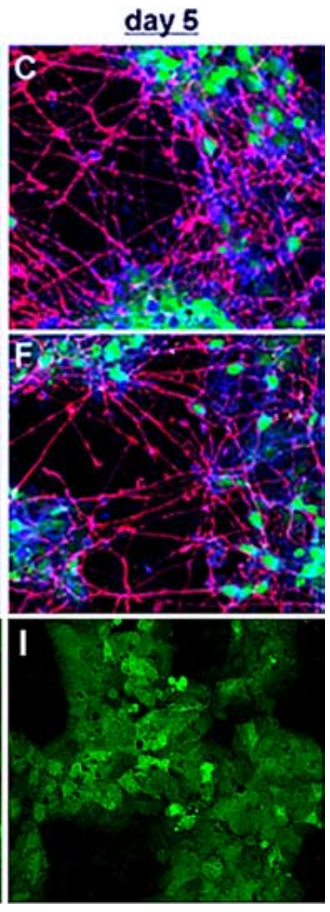

Figure 2. Differentiation of ES cells at $24 \mathrm{~h}, 72 \mathrm{~h}$, and $5 \mathrm{~d}$ in vitro. Photomicrographs illustrate eGFP (green), TUJ1 (red), and 列 政 $\sim 75 \%$ of TUJ1-positive cells were positive for VGLUT1 and VGLUT2. Uninduced ES cells (G-I) did not express TUJ1 or VGLUT1 or VGLUT2, even in the presence of NTFs.

(1:200; Roche Applied Science) for $1 \mathrm{~h}$ at room temperature in the dark. Sections were colabeled using antibody to TUJ1 (as above) visualized with an anti-mouse antibody conjugated to Alexa 594.

Quantitative assessments of stem cell number. Three sections (sections 11,16 and 21 from each of the five cochleae) were used for quantitative assessment of colabeling with eGFP, TUJ1 and VGLUT1/2 and adjacent sections $(12,17,22)$ for GFAP immunolabeling. Digital images were acquired on an Olympus FV-500 or Zeiss LSM510 confocal microscope and imported into MetaMorph Image Analysis (Universal Imaging) for quantitative assessment. All cells in the profile through the ST in the basal turn that were labeled at least $3 \times$ over background were counted as positive. The number of cells immunolabeled for TUJ1 (including those colabeled with eGFP), those labeled with eGFP only plus the number of GFAP immunolabeled cells from the adjacent section was determined for the basal most profile through ST. The percentage of TUJ1 cells with a glutamatergic phenotype was estimated by dividing the number of cells coimmunolabeling with VGLUT1/2 and TUJ1 by the total number of TUJ1 immunolabeled cells. The number of cells that coexpressed eGFP with TUJ1, VGLUT1/2, and GFAP was also determined.

Quantitative assessments of spiral ganglion neurons. The density of remaining spiral ganglion neurons was assessed in the three TUJ1 immunostained sections from guinea pigs $1-5$ as well as from three deafened guinea pigs without placement of stem cells, the latter being assessed 4 weeks after deafening. The number of TUJ1 immunostained neurons with a profile through the nucleus was determined in the two basal most profiles through Rosenthals canal and divided by the area of Rosenthals canal to give a measure of SGN density. 

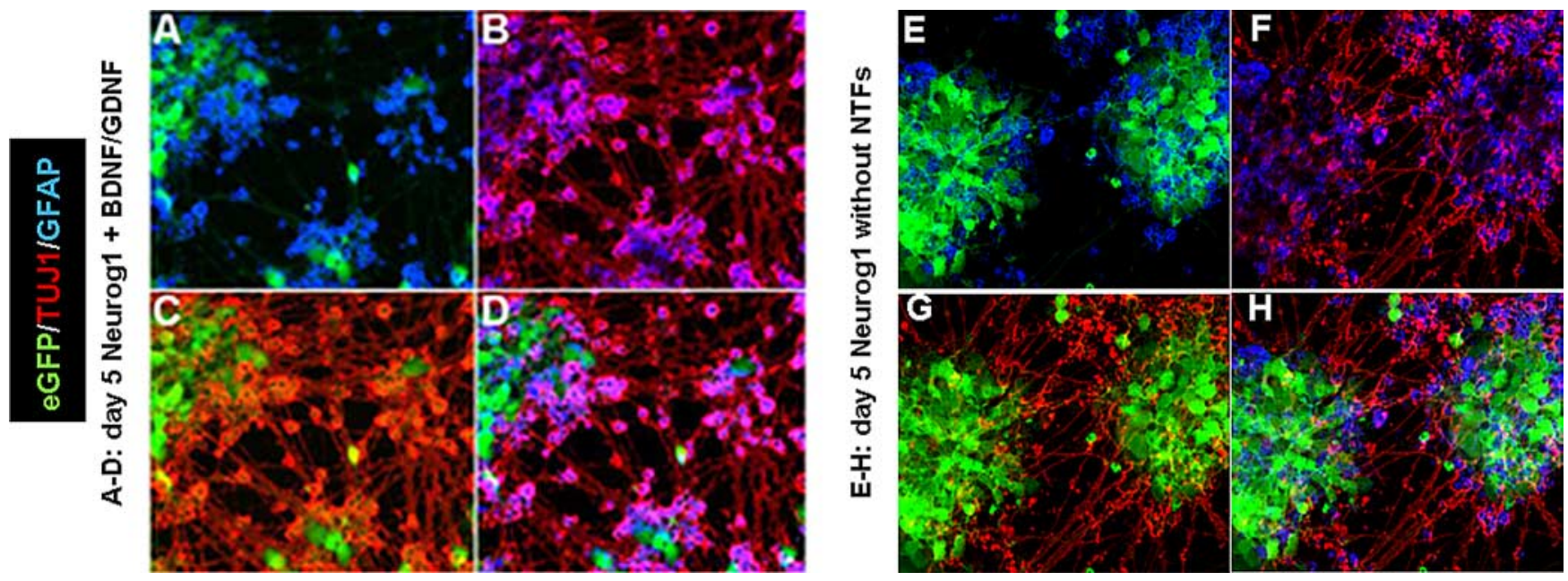

Figure 3. GFAP-positive cells appear by 5 d. Photomicrographs show combinations of eGFP (green), TUJ1 (red), and GFAP (blue) immunostaining at 5 d. $A, E$, eGFP and GFAP; $\boldsymbol{B}, \boldsymbol{F}, \mathrm{GFAP}$ and TUJ1; C, G, eGFP and TUJ1. All cells were exposed for $48 \mathrm{~h}$ to Dox to force expression of Neurog1. At $72 \mathrm{~h}$, the medium was changed to contain factors that enhance ES cell survival (see Materials and Methods), and cells were allowed to grow for 2 additional days. $\boldsymbol{A}-\boldsymbol{D}$, Cells were supplemented with the NTFs BDNF and GDNF throughout the $5 \mathrm{~d}$ in vitro differentiation. $\boldsymbol{E}$ - $\boldsymbol{H}$, Cells did not receive NTF supplements. Approximately $30 \%$ of cells in both Neurog1-induced treatment groups expressed the glial cell marker GFAP. GFAP ${ }^{+}$cells were not observed at earlier time points, and treatment with NTFs did not cause any difference in gliogenesis compared with untreated cells.

\section{Results}

\section{In vitro results}

$24 \mathrm{~h}$ in vitro

After $24 \mathrm{~h}$ in vitro K9 ES cells growing in neuronal differentiation medium displayed a typical ES cell morphology except many displayed small neurites in both the Dox only and in the Dox plus NTF treatment groups (Fig. 2). The concentration of Dox used in these studies induced a majority of cells to express the tetinducible Neurog1 transgene based on immunostaining (supplemental Fig. 1, available at www.jneurosci.org as supplemental material). The neuronal differentiation observed is consistent with previous reports on the effects of forced Neurog1 expression (Sun et al., 2001; Velkey, 2005). At this time, $54 \pm 8 \%$ of ES cells exposed to Dox alone expressed TUJ1, compared with $56 \pm 5 \%$ of ES cells treated with Dox and NTFs (Fig. 2). There was nearly complete overlap of TUJ1 and vesicular glutamate transporters VGLUT1 and VGLUT2 immunostaining. TUJ1-positive ES cells (50 $\pm 7 \%$; with or without NTFs) expressed VGLUT1 and VGLUT2. The ES cells that did not receive Dox did not express TUJ1, VGLUT1 or VGLUT2, nor did they show neurite outgrowth even when treated for $24 \mathrm{~h}$ with BDNF and GDNF. No GFAP immunostaining reactivity was observed in any of the four treatment groups at this time. See Figure 4 for summary.

\section{$72 h$ in vitro}

After $72 \mathrm{~h}$ in vitro, there was robust neuronal differentiation in Neurog1-induced ES cells, regardless of NTF supplementation. There was a significant increase in the percentage of induced cells expressing neuronal markers when exposed to BDNF and GDNF $(69 \pm 7 \%)$ compared with Neurog1-expressing cells not exposed to these NTFs $(54 \pm 10 \%)$ ( $p$ value $\leq 0.0073)$. Substantial neuritic networks formed in the Dox treated groups, but at this stage there was no apparent difference in neurite density between Dox only and Dox plus NTFs. At this time point the percentage of TUJ1-positive ES cells colabeled with VGLUT1/2 had increased in both Dox only (65 $\pm 5 \%$ ) and Dox plus NTF (69 $\pm 7 \%$ ) groups ( $p$ value $\leq 0.2493$ ). A very small number of cells expressed GFAP at this point $(<5 \%)$. ES cells in differentiation medium without Dox continued to lack evidence of neuronal or glial cell differentiation, and remained morphologically ES-cell like in shape and size.
$5 d$ in vitro

At $5 \mathrm{~d}$ in vitro, the number of GFAP-positive cells increased dramatically, with $\sim 30 \%$ of cells in both Neurog1-induced groups differentiating into a glial phenotype. After adjusting for GFAPpositive cells that colabeled with TUJ1, $56 \pm 3 \%$ of cells in the Dox plus NTF group formed neurons based on TUJ1 staining, compared with $45 \pm 6 \%$ in the Dox-only group $(p \leq 0.001)$ (Figs. 3, 4). Based on TUJ1 colabeling for VGLUT1/2, $75 \pm 11 \%$ of ES cell-derived neurons were glutamatergic in both treatment groups ( $p \leq 0.1649$ ). The Dox plus NTF condition appeared to have denser neuritic networks than the Dox only condition (unquantified), but the percentages of GFAP-positive cells in both conditions were approximately equal. Downregulation of eGFP increased between $72 \mathrm{~h}$ and $5 \mathrm{~d}$, whereas uninduced cells continued to fluoresce and did not express TUJ1, VGLUT1/2, or GFAP, regardless of NTF treatment.

\section{Gene expression}

Expression of Neurog1 was upregulated after Dox treatment, remaining elevated after $72 \mathrm{~h}$ but decreasing at $5 \mathrm{~d}$. Large upregulation of Ntrk2 and Ntrk3 (formerly TrkB and TrkC) as well as the $\alpha 1$ subunit of the GDNF receptor was observed at both $72 \mathrm{~h}$ and $5 \mathrm{~d}$ after treatment with Dox and NTFs (Fig. 5). Ntrk1 (formerly TrkA) showed only a small upregulation at $72 \mathrm{~h}$ that was no longer observed at $5 \mathrm{~d}$. A large upregulation of Brn3a, GATA3 and NeuroD1, which are all downstream targets of Neurog1 during normal SGN development (Huang et al., 2001; Karis et al., 2001), occurred at $72 \mathrm{~h}$. Expression of Brn3a and NeuroD1 decreased between $72 \mathrm{~h}$ and $5 \mathrm{~d}$, suggesting that cells express these transcription factors only transiently, which is consistent with expression profiles during normal SGN development (Fig. 5).

\section{In vivo results}

The in vivo studies used the treatment combination determined in vitro to give the highest percentage of neurons in vivo: $48 \mathrm{~h}$ of Dox exposure plus BDNF and GDNF supplementation. NTFs act as survival factors for SGN (Miller et al., 1997; Mou et al., 1997), and the combination of BDNF and GDNF was expected to further enhance survival of implanted ES cells reaching a SGN-like phenotype over the 4 week assessment period (Ulfendahl et al., 
2007). This was supported by our recent study showing intrascalar GDNF promoted survival of B5 ES cells placed into ST (Altschuler et al., 2008).

ES cells 4 weeks after placement

Numerous ES cells were present in scala tympani and modiolus of the guinea pig cochlea 4 weeks after implantation. A midmodiolar section typically contained 500-1000 ES cells, whereas a typical profile through the ST at the basal turn of the cochlear spiral contained 200-400 ES cells (supplemental Table, available at www. jneurosci.org as supplemental material). The greatest number of ES cells was found in the two basal-most profiles through ST, although ES cells were also seen in more apical profiles of the ST and scala vestibuli (SV) (Fig. 6). ES Cells were also present among remaining SGN, peripheral processes located in Rosenthal's canal (RC), and central processes in the modiolus (Fig. $7 A, B)$. Additional ES cells were present in small numbers around the region of the scar where hair cells formerly resided (Fig. $7 C)$, as well as in the spiral ligament of the lateral wall.

Undifferentiated ES cells were identified as eGFP positive and were typically small (10-12 $\mu \mathrm{m})$, round, and most commonly present throughout ST in small clusters (Fig. 6A,E). These cells were frequently seen among SGN and peripheral processes but less commonly in the modiolus. Many cells in the ST were positive for TUJ1, but few of these colabeled with eGFP. Cells that coexpressed TUJ1 and eGFP were usually larger than eGFP only cells and displayed a stellate or fusiform morphology typical of neurons (Figs. 6, 7, 8). A few undifferentiated cells were occasionally found in the scar region, where supporting cells had replaced inner and outer hair cells in the deafened organ of Corti (Fig. 7C,D), and others had invaded the spiral ligament/lateral wall as well as scala medium.

In situ hybridization of cochlear sections Immunostaining for TUJ1 identified hundreds of immunopositive cells in profiles through ST in mid-modiolar sections, but most of these did not express eGFP (supplemental Table, available at www.jneurosci.org as supplemental material; Figs. 6, 7, 8). Previous studies have similarly found stem cells placed into the cochlea downregulate reporters such as $\beta$-galactosidase and eGFP within weeks after placement (Corrales et al., 2006; Parker et al., 2007). One approach used XY FISH to identify implanted stem cells in the cochlea (Parker et al., 2007). We used a comparable approach, by combining immunocytochemistry for TUJ1 and FISH labeling for mouse genomic DNA. The FISH punctate nuclear labeling of

\section{Differentiation of Neurog1-induced mouse ES cells in vitro}
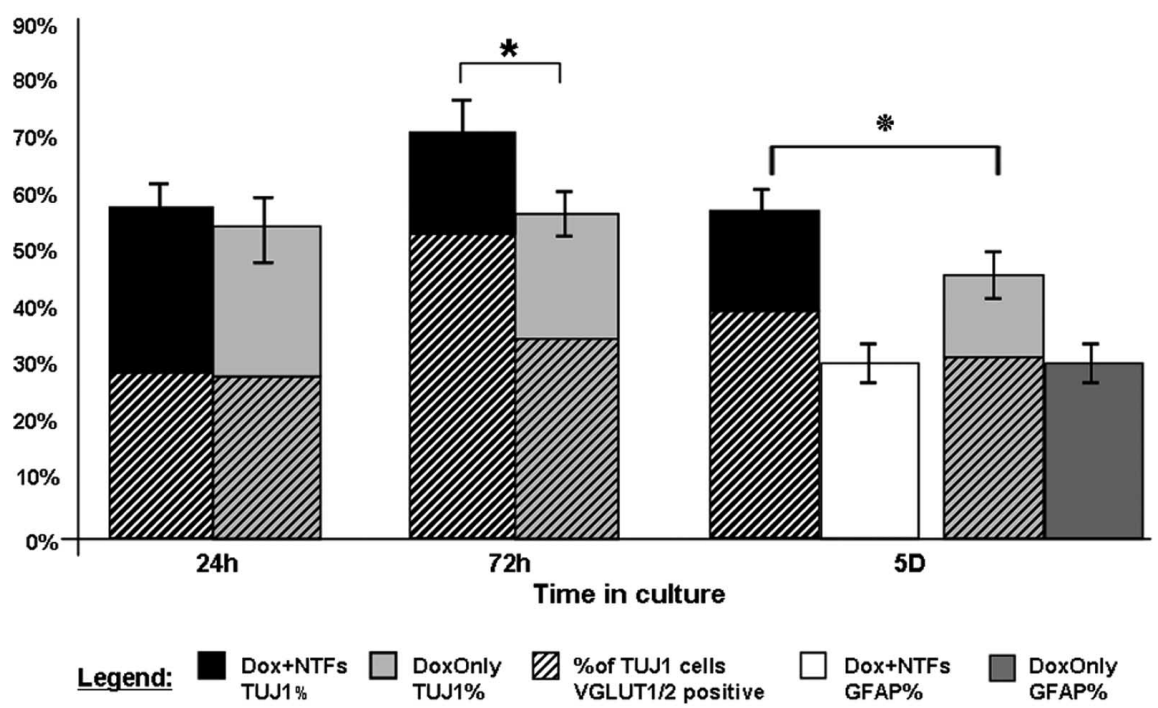

Figure 4. Glutamatergic neuronal and glial differentiation in vitro. After induction of the Neurog1 transgene, the percentage of ES cells positive for TUJ1 was taken as the total number of cells positive for TUJ1 divided by the total number of cells (eGFP-only cells + colabeled cells + TUJ1-only cells). ES-cell-derived neurons that coexpressed VGLUT1/2 and TUJ1 were quantified to determine the percentage of cells undergoing glutamatergic differentiation, which is represented by the hash marks within TUJ1-positive percentages. Few GFAP-positive cells ( $h$, but by $5 \mathrm{~d}$, robust glial differentiation was observed, with $\sim 30 \%$ of cells

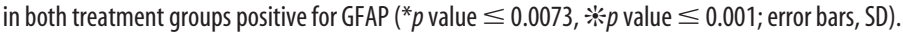

\section{Expression of SGN-related genes after $48 \mathrm{~h}$ Dox induction in vitro}

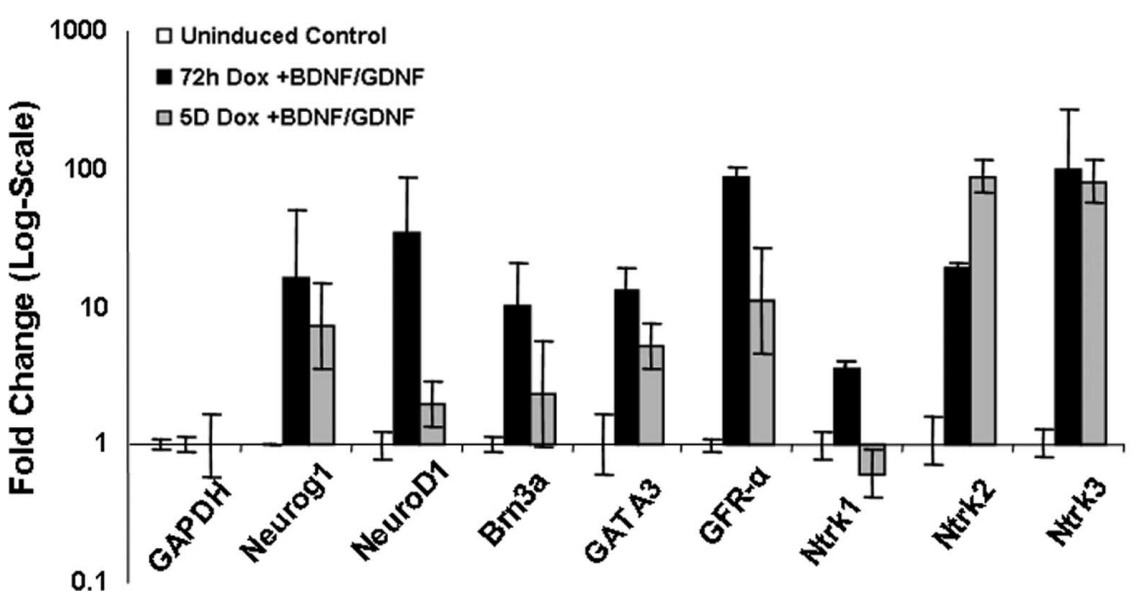

Figure 5. Gene expression at $72 \mathrm{~h}$ and $5 \mathrm{~d}$ in vitro. Expression of Neurog1, Brn3a, GATA3, NeuroD1, Ntrk1, Ntrk2, Ntrk3, and GFR $\alpha 1$ was analyzed at $72 \mathrm{~h}$ and $5 \mathrm{~d}$ relative to uninduced cells at $0 \mathrm{~h}$ (i.e., undifferentiated cells). qRT-PCR confirmed Doxinitiated Neurog1 expression, which results in large increases in Ntrk2 and Ntrk3 at both time points analyzed. Ntrk1 was less strongly expressed at $72 \mathrm{~h}$ and dropped at $5 \mathrm{~d}$. GFR $\alpha 1$ was also upregulated at $72 \mathrm{~h}$ and $5 \mathrm{~d}$. After termination of Dox treatment, Brn3a, GATA3, and NeuroD1, which are all transiently upregulated by Neurog1 during normal SGN development, decreased significantly between $72 \mathrm{~h}$ and $5 \mathrm{~d}$. The expression profiles of these genes suggest that an $\mathrm{SGN}$-like differentiation program may be initiated in ES cells forced to express Neurog1 for $48 \mathrm{~h}$.

$>90 \%$ of TUJ1 expressing cells in ST (Fig. $8 \mathrm{~A}$ ) confirmed that most if not all TUJ1-positive cells seen in other regions (e.g., SV or RC) were of ES cell origin, as well.

\section{Spiral ganglion neurons}

The remaining SGN at 4 weeks after deafening had a mean density of 6.7 SGN per $10,000 \mathrm{~mm}^{2} \pm 1.0$ (SD) compared with the normal density of 9.5 per $10,000 \mathrm{~mm}^{2} \pm 0.6$ from our normative data base (Miller et al., 2007). The density was further reduced to a mean of 4.8 per $10,000 \mathrm{~mm}^{2} \pm 1.8$ in GPs $1-5$, suggesting a 

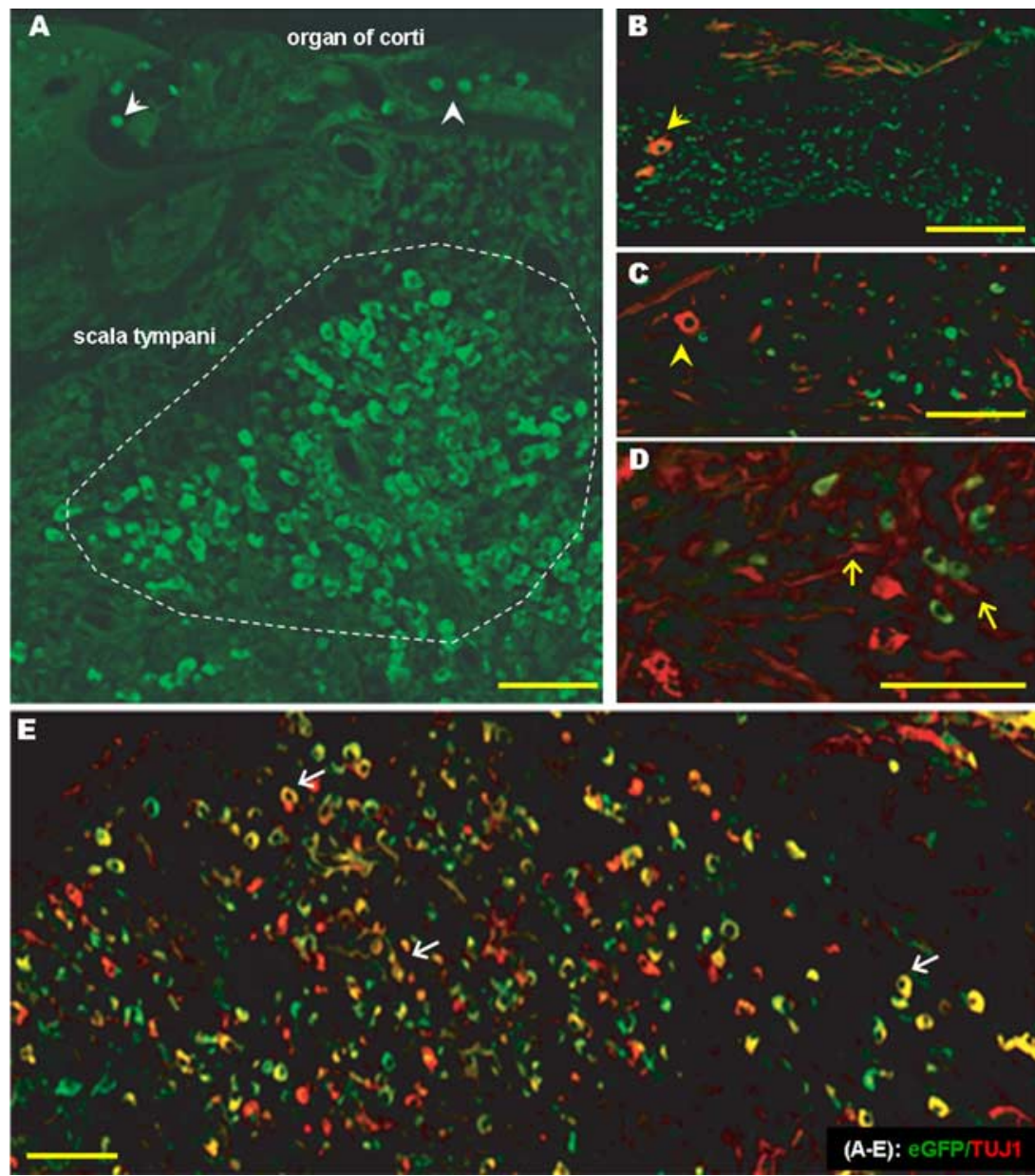

Figure 6. eGFP and TUJ1 expression in the basal-most profile of scala tympani (ST). Five week deafened guinea pigs were injected with 250,000 mouse ES cells in the ST/modiolar region, and cochleae were assessed 4 weeks after injection. $\boldsymbol{A}$, eGFPexpressing mouse ES cells were observed in ST (outlined); eGFP fluorescent cells could also be observed in the sulcus and scar region (white arrowheads). $B, C$, Many TUJ1-positive cells (yellow arrowheads) did not express eGFP, suggesting that the UbC promoter may have been methylated. D, TUJ1-positive neurites (yellow arrows) sprouting from eGFP-positive and TUJ1-positive cells in ST. E, eGFP and TUJ1 colocalization (white arrows). Scale bars, $50 \mu \mathrm{m}$.

continued loss of SGN over the longer period after deafening (decrease in density over 4 weeks not significant). No significant differences in SGN density between the right cochleae (no ES cells implanted) and left cochleae (ES cells implanted, with Dox and NTFs) of GP1-5. The mean SGN density in the right, nontreated ear was only slightly lower at 4.0 per $10,000 \mathrm{~mm}^{2} \pm 1.2$. See Figure $7 A$ for example.

\section{Assessment of ES cell phenotype in vivo}

\section{Neuronal, glutamatergic differentiation of ES cells in vivo}

Numerous TUJ1-positive cells were seen in profiles through the ST and SV (Figs. 6, 7, 8). Cells that were TUJ1 positive and eGFP negative had a more neuronal appearance compared with cells that coexpressed eGFP, the former displaying large spherical cell bodies and fusiform extensions. Cells in these compartments were considered of ES cell origin based on the high percentage in various compartments that colabeled for mouse genomic DNA (Fig. 8A). Some large spindle-shaped ES cell-derived neurons expressed both eGFP and TUJ1 and were present among SGN. These cells were often present in modiolar locations atypical of native SGN, suggesting they may be of ES cell origin (Fig. 7A-C).

Sections that were colabeled for VGLUT1/2 and TUJ1 with eGFP were used for quantitative evaluation. An estimate was made of the number of ES cells in the most basal ST profile reaching a neuronal phenotype based on TUJ1 immunostaining by dividing the number of TUJ1- positive neurons in the profile by the total of TUJ1and eGFP-only-positive neurons plus the number of GFAP-positive cells (taken from the adjacent section). Results are shown in Figure 9 and supplemental Table, available at www.jneurosci.org as supplemental material. The percentage of TUJ1-positive cells ranged from a low of $52 \%$ (GP 1) to a high of $78 \%$ (GP 4), with a mean across the five experimental guinea pigs of $66 \%$. These results are summarized in Figure 9 and supplemental Table, available at www.jneurosci.org as supplemental material. This compares to $56 \%$ of stem cells reaching a neuronal phenotype with comparable treatments by $5 \mathrm{~d}$ in vitro (Fig. 4).

Colabeling for TUJ1 and VGLUT1 and VGLUT2 (Fig. 8C) was used to determine the percentage of ES cells with a glutamatergic phenotype in the basal-most profiles of ST. ES cell-derived neurons expressing VGLUT1/2 ranged from $72 \%$ (GP 2) to $89 \%$ (GP 5), with a mean across the five guinea pigs of $79 \%$. This compares very closely to the $75 \%$ of ES cell-derived neurons considered glutamatergic after comparable treatments in vitro.

The percentage of ES cells reaching a neuronal phenotype was significantly lower in the three animals that did not receive $2 \mathrm{~d}$ of Dox to induce Neurog1 expression (GP 6-8). In a recent study, B5 stem cells received intrascalar GDNF after placement into ST, but these cells did not contain the Neurog1 transgene. The percentage reaching a neuronal phenotype (27\%) was well below what was observed in GP1-5 with forced Neurog1 expression (Altschuler et al., 2008).

\section{Immunostaining for downstream targets of Neurog1}

Large numbers of GATA3-positive cells were found in profiles through ST, many of which colabeled for TUJ1 (Fig. 8E-G). There were also a few GATA3-immunopositive cells that did not colabel with TUJ1, whereas colabeling of GATA3 with eGFP was rare. Fewer stem cells were immunopositive for NeuroD1 and these were more likely to colabel with eGFP than TUJ1 (Fig. 8D).

\section{GFAP immunostaining (astrocyte differentiation)}

In 4 of the 5 Neurog 1 induced animals (GP2-5), $<8 \%$ of ES cells in basal ST profiles were positive for GFAP, an astrocyterestricted intermediate filament and glial phenotype marker (Fig. $8 B$ ). The three control animals that received stem cells without Neurog1 induction had similar percentages of GFAP-positive ES cells $(<8 \%)$. In one animal (GP 1), however, 39\% of cells were GFAP positive (Fig. 9; supplemental Table, available at www. jneurosci.org as supplemental material). Most of the GFAPpositive cells were not colabeled with eGFP, suggesting that expression was downregulated during differentiation into a glial phenotype, as was seen in vitro. The UbC promoter used to drive 
eGFP expression was likely methylated during differentiation as observed in vitro.

\section{Discussion}

The proneural bHLH transcription factor Neurog1 has previously been shown to strongly promote neuronal differentiation in precursors of various germ layers (Sun et al., 2001; Kim et al., 2004, 2008). Neurog1 is also critical for SGN differentiation during development, but the only experimental evidence linking it to glutamatergic specification has come from knock-out models, where Neurog1 was found to play a role in glutamatergic vs gabaergic fate choice (Schuurmans et al., 2004). In the current investigation, differentiation was controlled in vivo and in vitro using a stepwise protocol in which the Neurog1 transgene was induced, followed by application of neurotrophic factors known to act on receptors downstream of Neurog1. This enabled implantation of undifferentiated ES cells with differentiation induced subsequent to placement with the hope that implanting undifferentiated cells would bypass the immune response.

We show that physiologically relevant 48 h expression of Neurog 1 efficiently promotes ES cell differentiation into a glutamatergic, neuronal phenotype (56\% in vitro and $66 \%$ in vivo). This is a basic requirement for auditory nerve replacement, because SGN primarily rely on glutamate for transmission of sensory information to the CNS (Eybalin, 1993).

Inclusion of NTFs may have provided additional support for SGN-like cell survival (Mou et al., 1997; Shepherd et al., 2008), although others have shown that they can also function to enhance differentiation (for review, see Huang and Reichardt, 2001). It is known that cochlear electrical stimulation can also enhance SGN survival in synergy with NTF application (for review, see Green et al., 2008), and stimulation may promote neuronal differentiation in ES cells in vitro (Yamada et al., 2007). We found that in vitro application of BDNF and GDNF resulted in a slight increase in neuronal differentiation after Neurogl expression (56\% compared with $45 \%$ without NTFs at $5 \mathrm{~d}$ ) and caused a notable increase in neurite outgrowth, although the latter was not quantified.

The mechanism of BDNF and GDNF action is likely by upregulating NTF receptors by SGN-specific transcription factors Brn3a, NeuroD1, and GATA3. This process has been documented in development (Huang et al., 2001; Calella et al., 2007), and we observed that with differentiation, ES cells expressed these markers both in vitro and in vivo. The expression of the GDNF receptor, along with BDNF receptor Ntrk2 and NT-3 receptor Ntrk3, remained elevated by $5 \mathrm{~d}$, whereas Ntrk1 was lost at $5 \mathrm{~d}$ after a slight upregulation at $72 \mathrm{~h}$. This provides further evidence that Neurog1-induced ES cells are SGN-like, as a majority of vertebrate VIII ${ }^{\text {th }}$ nerve ganglia express Ntrk2 and Ntrk3 and to a lesser extent Ntrk1 depending on the species (Don et al., 1997; von Bartheld and Fritzsch, 2006; Catania et al., 2007).

Previous studies aimed at inducing differentiation of uncommitted precursors in the cochlea found that a majority of cells became glia rather than the target neuronal phenotype (Hu et al.,
2004, 2005a,b; Tamura et al., 2004; Nicholl et al., 2005; Coleman et al., 2006, 2007; Corrales et al., 2006; Parker et al., 2007; Ulfendahl et al., 2007). In our studies, we found only one of the five experimental animals had a significant percentage of GFAPpositive cells, with $30 \%$ reaching a glial phenotype, whereas the other four animals had $<1 \%$. In the Dox-treated groups at $72 \mathrm{~h}$ in vitro, various glial-like derivatives began populating the dish at percentages similar to the one in vivo outlier $(\sim 30 \%$ of cells under both conditions were GFAP positive, indicating BDNF and GDNF did not influence gliogenesis). Glial cells of the inner ear, however, derive from neural crest cells (Jessen and Mirsky, 2005), a different subpopulation of neural precursors than those that form the spiral ganglion.

The introduction of factors to prolong ES cell survival at this time point likely influenced the presence of additional neural phenotypes in the dish. The knock-out serum replacement added to the medium contains bone morphogenetic proteins, which may have influenced astrocyte differentiation in the present study (Mabie et al., 1997; Gossrau et al., 2007; Imura et al., 2008). The emergence of glia at this time is consistent with the role of proneural bHLH factors in promoting neurogenesis while inhibiting gliogenesis, the latter proceeding once bHLH inhibition has been lifted (Ma et al., 1998; Nieto et al., 2001; Sun et al., 2001). It is clear from our studies that a subpopulation of ES cells does not terminally differentiate by $72 \mathrm{~h}$ and can be influenced by components in the medium to differentiate into an astrocyte phenotype.

Random integration of the eGFP transgene resulted in downregulation with differentiation, likely via normal epigenetic mechanisms that silence foreign DNA. This problem might be alleviated by using stronger promoters (Chung et al., 2002; Hong et al., 2007), but whether these will remain constitutively active during differentiation with Neurog1 is not likely. More promising approaches would be to use an insulator, a special class of DNA placed 

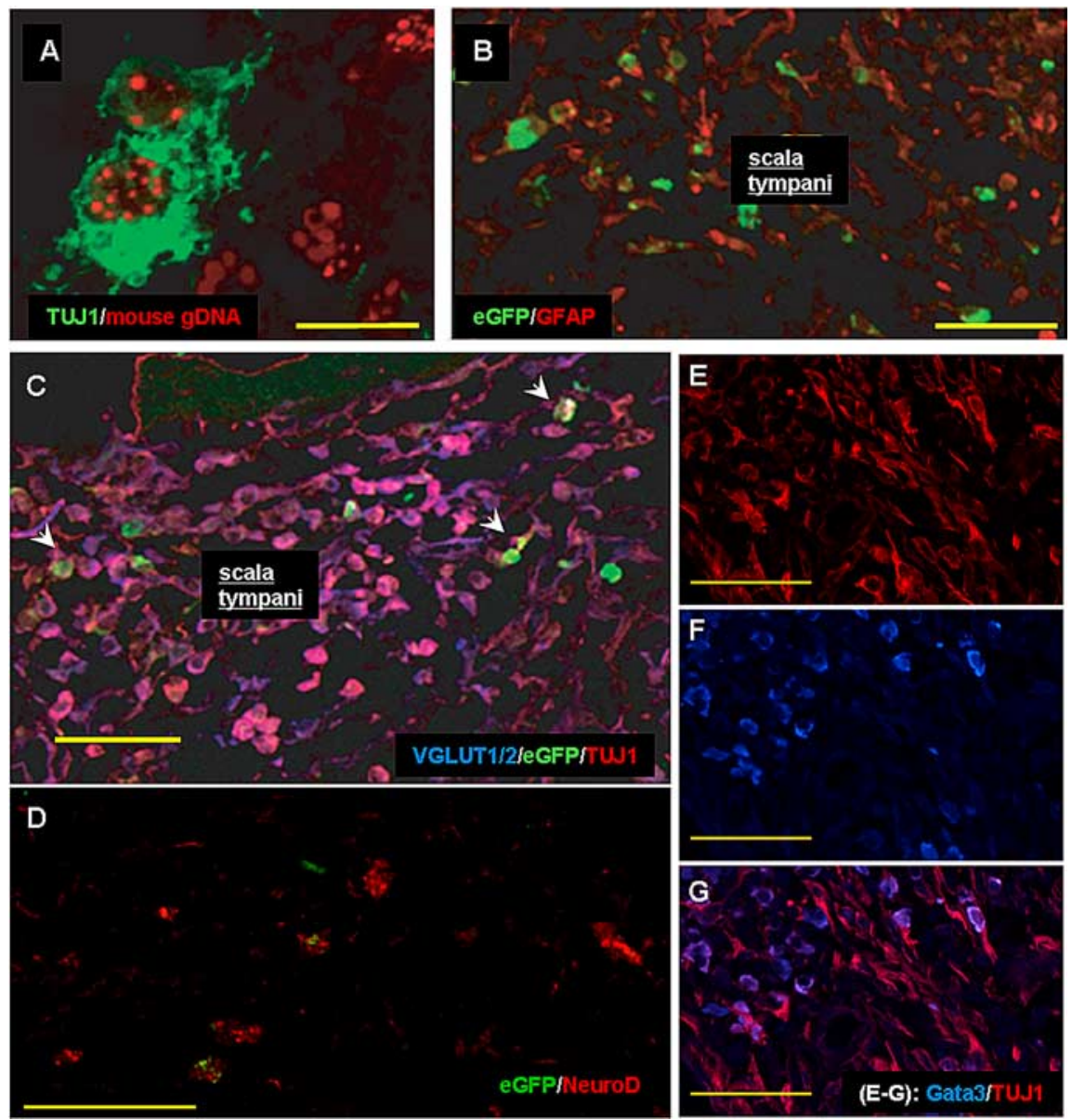

Figure 8. Phenotype differentiation of ES cells in vivo. $\boldsymbol{A}$, In situ hybridization for mouse genomic DNA (red) and TUJ1 (green) confirmed that cells in the scala tympani (ST) and modiolar regions were of ES cell origin. $\boldsymbol{B}$, In 4 of the 5 experimental animals, GFAP-positive cells were present in small numbers among eGFP-positive cells located in ST. C, There are many VGLUT1/2- and TUJ1-colabeled cells in ST (pink); these only rarely colabeled with EGFP (arrowheads). D, Few cells in ST of basal cochlea expressed NeuroD (red) and some colabeled with eGFP. $\boldsymbol{E}-\boldsymbol{G}$, Immunolabeling for TUJ1 (E) and GATA3 (F), combined in $\boldsymbol{G}$, identified many colabeled cells (pink/violet) in basal ST as well as many cells expressing only TUJ1 (red) or only GATA3 (blue). Scale bars, $50 \mu \mathrm{m}$.

tory nerve remaining (Pfingst, 1990; Kileny et al., 1991; Blamey et al., 1996; Skinner et al., 1997; Incesulu and Nadol, 1998; Rubinstein et al., 1999; Miller et al., 2000). At the same time, a more substantial loss of SGN experimentally may enhance migration and survival of implanted ES cells, possibly attributable to the elevated expression of trophic factors in the damaged cochlea (Corrales et al., 2006; Sekiya et al., 2006; Ulfendahl et al., 2007). Replacement of auditory nerve using an approach similar to the one we have outlined could therefore be of great value to those with little or no nerve remaining. Our results demonstrate that recapitulating developmental cues can promote differentiation of ES cells toward a phenotype expressing markers of SGN development. We show this differentiation occurs at high percentages both in vitro and without inducing an immune response in vivo. Future in vivo and in vitro studies are necessary to determine if these ES-cell-derived neurons are capable of functional integration to replace auditory nerve and improve the efficacy of cochlear prostheses.

\section{References}

Altschuler RA, O'Shea KS, Miller JM (2008) Stem cell transplantation for auditory nerve replacement. Hear Res 242:110-116.

Blamey P, Arndt P, Bergeron F, Bredberg G, Brimacombe J, Facer G, Larky J, Lindström B, Nedzelski J, Peterson A, Shipp D, Staller S, Whitford L (1996) Factors affecting auditory performance of postlinguistically deaf adults using cochlear implants. Audiol Neurootol 1:293-306.

Calella AM, Nerlov C, Lopez RG, Sciarretta C, von Bohlen und Halbach O, Bereshchenko O,

upstream of a promoter to prevent heterochromatin-mediated downregulation of the transgene (Geyer and Clark, 2002), or targeted expression in a constitutively active site in the mouse ES cell genome. Downregulation of eGFP complicated identification of implanted ES cells after differentiation, particularly when the cells become integrated into native tissue containing neurons and glia that are positive for the same neural markers. ES cells could be identified using a Y chromosome marker (Parker et al., 2007), because this cell line was derived from a male mouse blastocyst, but this would only enable identification of nuclei, not neurites emanating from cells of ES origin. One potential approach to visualizing fine cell processes would be to employ a construct in which the microtubule-associated protein Tau is fused with a fluorescent reporter, thereby remaining anchored to the cytoskeleton of ES cells as they differentiate (Pratt et al., 2000; Wernig et al., 2002).

Degeneration of the auditory nerve occurs subsequent to the loss of inner hair cells (Webster and Webster, 1981), and neither cell type is normally replaced by any endogenous mechanisms. Some restoration of hearing can be obtained from a cochlear implant (also known as cochlear prosthesis), which bypasses IHC function through coding acoustic stimuli into an electrical impulses delivered directly to remaining auditory nerve. Cochlear implant performance, however, depends on the amount of audi-
Minichiello L (2007) Neurotrophin/Trk receptor signaling mediates C/EBPalpha, -beta and NeuroD recruitment to immediate-early gene promoters in neuronal cells and requires C/EBPs to induce immediateearly gene transcription. Neural Develop 2:4.

Catania S, Germanà A, Cabo R, Ochoa-Erena FJ, Guerrera MC, Hannestad J, Represa J, Vega JA (2007) Neurotrophin and Trk neurotrophin receptors in the inner ear of Salmo salar and Salmo trutta. J Anat 210:78-88.

Chung S, Andersson T, Sonntag KC, Björklund L, Isacson O, Kim KS (2002) Analysis of different promoter systems for efficient transgene expression in mouse embryonic stem cell lines. Stem Cells 20:139-145.

Coleman B, Hardman J, Coco A, Epp S, de Silva M, Crook J, Shepherd R (2006) Fate of embryonic stem cells transplanted into the deafened mammalian cochlea. Cell Transplant 15:369-380.

Coleman B, Fallon JB, Pettingill LN, de Silva MG, Shepherd RK (2007) Auditory hair cell explant co-cultures promote the differentiation of stem cells into bipolar neurons. Exp Cell Res 313:232-243.

Corrales CE, Pan L, Li H, Liberman MC, Heller S, Edge AS (2006) Engraftment and differentiation of embryonic stem cell-derived neural progenitor cells in the cochlear nerve trunk: growth of processes into the organ of Corti. J Neurobiol 66:1489-1500.

Don DM, Newman AN, Micevych PE, Popper P (1997) Expression of brainderived neurotrophic factor and its receptor mRNA in the vestibuloauditory system of the bullfrog. Hear Res 114:10-20.

Drukker M, Katchman H, Katz G, Even-Tov Friedman S, Shezen E, Hornstein E, Mandelboim O, Reisner Y, Benvenisty N (2006) Human embryonic stem cells and their differentiated derivatives are less susceptible to immune rejection than adult cells. Stem Cells 24:221-229. 
Eybalin M (1993) Neurotransmitters and neuromodulators of the mammalian cochlea. Physiol Rev 73:309-373.

Fritzsch B (2003) Development of inner ear afferent connections: forming primary neurons and connecting them to the developing sensory epithelia. Brain Res Bull 60:423-433.

Geyer PK, Clark I (2002) Protecting against promiscuity: the regulatory role of insulators. Cell Mol Life Sci 59:2112-2127.

Gossrau G, Thiele J, Konang R, Schmandt T, Brüstle O (2007) Bone morphogenetic protein-mediated modulation of lineage diversification during neural differentiation of embryonic stem cells. Stem Cells 25:939-949.

Green SH, Altschuler RA, Miller JM (2008) Cell death and cochlea protection. In: Auditory trauma, protection and repair (Schacht J, Popper AN, Fay RR, eds), pp 275-320. New York: Springer.

Hong S, Hwang DY, Yoon S, Isacson O, Ramezani A, Hawley RG, Kim KS (2007) Functional analysis of various promoters in lentiviral vectors at different stages of in vitro differentiation of mouse embryonic stem cells. Mol Ther 15:1630-1639.

Hu Z, Ulfendahl M, Olivius NP (2004) Central migration of neuronal tissue and embryonic stem cells following transplantation along the adult auditory nerve. Brain Res 1026:68-73.

Hu Z, Andäng M, Ni D, Ulfendahl M (2005a) Neural cograft stimulates the survival and differentiation of embryonic stem cells in the adult mammalian auditory system. Brain Res 1051:137-144.

Hu Z, Wei D, Johansson CB, Holmström N, Duan M, Frisén J, Ulfendahl M (2005b) Survival and neural differentiation of adult neural stem cells transplanted into the mature inner ear. Exp Cell Res 302:40-47.

Huang EJ, Reichardt LF (2001) Neurotrophins: roles in neuronal development and function. Annu Rev Neurosci 24:677-736.

Huang EJ, Liu W, Fritzsch B, Bianchi LM, Reichardt LF, Xiang M (2001) Brn3a is a transcriptional regulator of soma size, target field innervation and axon pathfinding of inner ear sensory neurons. Development 128:2421-2432.

Imura T, Tane K, Toyoda N, Fushiki S (2008) Endothelial cell-derived bone morphogenetic proteins regulate glial differentiation of cortical progenitors. Eur J Neurosci 27:1596-1606.

Incesulu A, Nadol JB Jr (1998) Correlation of acoustic threshold measures and spiral ganglion cell survival in severe to profound sensorineural hearing loss: implications for cochlear implantation. Ann Otol Rhinol Laryngol 107:906-911.

Jessen KR, Mirsky R (2005) The origin and development of glial cells in peripheral nerves. Nat Rev Neurosci 6:671-682.

Karis A, Pata I, van Doorninck JH, Grosveld F, de Zeeuw CI, de Caprona D, Fritzsch B (2001) Transcription factor GATA-3 alters pathway selection of olivocochlear neurons and affects morphogenesis of the ear. J Comp Neurol 429:615-630.

Kileny PR, Zimmerman-Phillips S, Kemink JL, Schmaltz SP (1991) Effects of preoperative electrical stimulability and historical factors on performance with multichannel cochlear implant. Ann Otol Rhinol Laryngol 100:563-568.

Kim S, Yoon YS, Kim JW, Jung M, Kim SU, Lee YD, Suh-Kim H (2004) Neurogenin 1 is sufficient to induce neuronal differentiation of embryonal carcinoma P19 cells in the absence of retinoic acid. Cell Mol Neurobiol 24:343-356.

Kim SS, Yoo SW, Park TS, Ahn SC, Jeong HS, Kim JW, Chang DY, Cho KG, Kim SU, Huh Y, Lee JE, Lee SY, Lee YD, Suh-Kim H (2008) Neural Induction with Neurogenin1 Increases the Therapeutic Effects of Mesenchymal Stem Cells in the Ischemic Brain. Stem Cells 26:2217-2228.
Kim WY, Fritzsch B, Serls A, Bakel LA, Huang EJ, Reichardt LF, Barth DS, Lee JE (2001) NeuroD-null mice are deaf due to a severe loss of the inner ear sensory neurons during development. Development 128:417-426.

Kyba M, Perlingeiro RC, Daley GQ (2002) HoxB4 confers definitive lymphoid-myeloid engraftment potential on embryonic stem cell and yolk sac hematopoietic progenitors. Cell 109:29-37.

Livak KJ, Schmittgen TD (2001) Analysis of relative gene expression data using real-time quantitative PCR and the 2(-Delta Delta C(T)) Method. Methods 25:402-408.

Ma Q, Chen Z, del Barco Barrantes I, de la Pompa JL, Anderson DJ (1998) neurogenin 1 is essential for the determination of neuronal precursors for proximal cranial sensory ganglia. Neuron 20:469-482.

Ma Q, Anderson DJ, Fritzsch B (2000) Neurogenin 1 null mutant ears develop fewer, morphologically normal hair cells in smaller sensory epithelia devoid of innervation. J Assoc Res Otolaryngol 1:129-143.

Mabie PC, Mehler MF, Marmur R, Papavasiliou A, Song Q, Kessler JA (1997) Bone morphogenetic proteins induce astroglial differentiation of oligodendroglial-astroglial progenitor cells. J Neurosci 17:4112-4120.

McCormick MB, Tamimi RM, Snider L, Asakura A, Bergstrom D, Tapscott SJ (1996) NeuroD2 and neuroD3: distinct expression patterns and transcriptional activation potentials within the neuroD gene family. Mol Cell Biol 16:5792-5800.

Miller AL, Morris DJ, Pfingst BE (2000) Effects of time after deafening and implantation on guinea pig electrical detection thresholds. Hear Res 144:175-186.

Miller JM, Chi DH, O’Keeffe LJ, Kruszka P, Raphael Y, Altschuler RA (1997) Neurotrophins can enhance spiral ganglion cell survival after inner hair cell loss. Int J Dev Neurosci 15:631-643.

Miller JM, Le Prell CG, Prieskorn DM, Wys NL, Altschuler RA (2007) Delayed neurotrophin treatment following deafness rescues spiral ganglion cells from death and promotes regrowth of auditory nerve peripheral 
processes: effects of brain-derived neurotrophic factor and fibroblast growth factor. J Neurosci Res 85:1959-1969.

Mou K, Hunsberger CL, Cleary JM, Davis RL (1997) Synergistic effects of BDNF and NT-3 on postnatal spiral ganglion neurons. J Comp Neurol 386:529-539.

Murphy CL, Polak JM (2002) Differentiating embryonic stem cells: GAPDH, but neither HPRT nor beta-tubulin is suitable as an internal standard for measuring RNA levels. Tissue Eng 8:551-559.

Nicholl AJ, Kneebone A, Davies D, Cacciabue-Rivolta DI, Rivolta MN, Coffey P, Holley MC (2005) Differentiation of an auditory neuronal cell line suitable for cell transplantation. Eur J Neurosci 22:343-353.

Nieto M, Schuurmans C, Britz O, Guillemot F (2001) Neural bHLH genes control the neuronal versus glial fate decision in cortical progenitors. Neuron 29:401-413.

Parker MA, Corliss DA, Gray B, Anderson JK, Bobbin RP, Snyder EY, Cotanche DA (2007) Neural stem cells injected into the sound-damaged cochlea migrate throughout the cochlea and express markers of hair cells, supporting cells, and spiral ganglion cells. Hear Res 232:29-43.

Pfingst BE (1990) Changes over time in thresholds for electrical stimulation of the cochlea. Hear Res 50:225-236.

Pratt T, Sharp L, Nichols J, Price DJ, Mason JO (2000) Embryonic stem cells and transgenic mice ubiquitously expressing a tau-tagged green fluorescent protein. Dev Biol 228:19-28.

Prieskorn DM, Miller JM (2000) Technical report: chronic and acute intracochlear infusion in rodents. Hear Res 140:212-215.

Robertson NJ, Brook FA, Gardner RL, Cobbold SP, Waldmann H, Fairchild PJ (2007) Embryonic stem cell-derived tissues are immunogenic but their inherent immune privilege promotes the induction of tolerance. Proc Natl Acad Sci U S A 104:20920-20925.

Rubinstein JT, Parkinson WS, Tyler RS, Gantz BJ (1999) Residual speech recognition and cochlear implant performance: effects of implantation criteria. Am J Otol 20:445-452.

Schorpp M, Jäger R, Schellander K, Schenkel J, Wagner EF, Weiher H, Angel P (1996) The human ubiquitin C promoter directs high ubiquitous expression of transgenes in mice. Nucleic Acids Res 24:1787-1788.

Schuurmans C, Armant O, Nieto M, Stenman JM, Britz O, Klenin N, Brown C, Langevin LM, Seibt J, Tang H, Cunningham JM, Dyck R, Walsh C, Campbell K, Polleux F, Guillemot F (2004) Sequential phases of cortical specification involve Neurogenin-dependent and -independent pathways. EMBO J 23:2892-2902.
Sekiya T, Kojima K, Matsumoto M, Kim TS, Tamura T, Ito J (2006) Cell transplantation to the auditory nerve and cochlear duct. Exp Neurol 198:12-24.

Shepherd RK, Coco A, Epp SB (2008) Neurotrophins and electrical stimulation for protection and repair of spiral ganglion neurons following sensorineural hearing loss. Hear Res 242:100-109.

Skinner MW, Holden LK, Holden TA (1997) Parameter selection to optimize speech recognition with the Nucleus implant. Otolaryngol Head Neck Surg 117:188-195.

Sun Y, Nadal-Vicens M, Misono S, Lin MZ, Zubiaga A, Hua X, Fan G, Greenberg ME (2001) Neurogenin promotes neurogenesis and inhibits glial differentiation by independent mechanisms. Cell 104:365-376.

Tamura T, Nakagawa T, Iguchi F, Tateya I, Endo T, Kim TS, Dong Y, Kita T, Kojima K, Naito Y, Omori K, Ito J (2004) Transplantation of neural stem cells into the modiolus of mouse cochleae injured by cisplatin. Acta Otolaryngol Suppl:65-68.

Ulfendahl M, Hu Z, Olivius P, Duan M, Wei D (2007) A cell therapy approach to substitute neural elements in the inner ear. Physiol Behav 92:75-79.

Velkey JM (2005) Lineage differentiation of mouse embryonic stem cells. Ann Arbor, MI: University of Michigan.

von Bartheld CS, Fritzsch B (2006) Comparative analysis of neurotrophin receptors and ligands in vertebrate neurons: tools for evolutionary stability or changes in neural circuits? Brain Behav Evol 68:157-172.

Webster M, Webster DB (1981) Spiral ganglion neuron loss following organ of Corti loss: a quantitative study. Brain Res 212:17-30.

Wernig M, Tucker KL, Gornik V, Schneiders A, Buschwald R, Wiestler OD, Barde YA, Brüstle O (2002) Tau EGFP embryonic stem cells: an efficient tool for neuronal lineage selection and transplantation. J Neurosci Res 69:918-924.

Wulff BS, O'Hare MM, Boel E, Theill LE, Schwartz TW (1990) Partial processing of the neuropeptide $\mathrm{Y}$ precursor in transfected CHO cells. FEBS Lett 261:101-105.

Yamada M, Tanemura K, Okada S, Iwanami A, Nakamura M, Mizuno H, Ozawa M, Ohyama-Goto R, Kitamura N, Kawano M, Tan-Takeuchi K, Ohtsuka C, Miyawaki A, Takashima A, Ogawa M, Toyama Y, Okano H, Kondo T (2007) Electrical stimulation modulates fate determination of differentiating embryonic stem cells. Stem Cells 25:562-570. 